\title{
Assessment of climate change impact on different pigeonpea maturity groups in north Indian condition
}

\author{
M.K. YADAV $* 1$, C. PATEL ${ }^{2}$, R.S. SINGH ${ }^{1}$, K.K. SINGH ${ }^{3}$, R. BALASUBRAMANIAN ${ }^{4}$, R.K. MALL ${ }^{5}$, \\ M.K. SINGH ${ }^{6}$, S.M. SINGH ${ }^{1}$ and S.K.YADAV ${ }^{7}$ \\ ${ }^{1}$ Department of Geophysics, Institute of Science, BHU, Varanasi-221005 \\ ${ }^{2}$ Department of Farm Engineering, Institute of Agricultural Sciences, BHU, Varanasi-221005 \\ ${ }^{3}$ India Meteorological Department, New Delhi-10003 \\ ${ }^{4}$ India Meteorological Department, Pune-411005 \\ ${ }^{5}$ DST-Mahamana Centre of Excellence in Climate Change Research, IESD, BHU, Varanasi-221005 \\ ${ }^{6}$ Department of Agronomy, Institute of Agricultural Sciences, BHU, Varanasi-221005 \\ ${ }^{7}$ Indian Institute of Sugarcane Research, Uttar Pradesh 226002 \\ *Corresponding author E-mail: manojagro@gmail.com
}

\begin{abstract}
The CROPGRO-pigeonpea model embedded in DSSAT v4.7.5 was used to assess the impact of climate change on phenology and grain yield of reference genotype of different pigeonpea maturity groups. The impact of climate change delayed reproductive stages (anthesis, maturity) and decreased grain yield of reference genotype of different pigeonpea maturity groups were evident in all scenarios. Short duration genotypes (MN5, ICPL88039, Prabhat, UPAS120) showed progressively higher decrease in yield as compared to medium (Maruti, Asha, ICP7035) and long (Bahar, MAL13) duration genotypes with each successive increase in scenatio from RCP2.6 to RCP8.5 and projected year from 2010 to 2095. Anthesis was delayed 9 days in MN5 to 20 days in Bahar and maturity delayed 15 days in MN5 to 24 days in Bahar with RCP 8.5 in year 2095 in comparison to RCP2.6 in years 2010, whereas, grain yield was decreased $14 \%$ in Bahar to $66 \%$ in MN5 among genotypes of different maturity groups.
\end{abstract}

Key words: MarkSim, GCM, RCP, DSSAT, climate change, pigeonpea, maturity group

The Earth's climate is projected to undergo marked changes over the $21^{\text {st }}$ century due to natural processes and anthropogenic factors (IPCC, 2014). As known that pigeonpea is second most grain legume stable in India, therefore climate change impacts on its production could have broad and national repercussions on food and nutritional security. The pigeonpea production is highly variable due to climatic variability. There is a great challenge for sustainable pigeonpea production in the country. The RCPs quantitatively describe and provide time and space dependent trajectories of anthropogenic greenhouse gases and pollutants together with their collective radiative forcing, and are used as input to climate models (IPCC, 2014). Global circulation models and process-based crop models have been used in different studies assessing the potential impacts of climate change on crop production. MarkSim DSSAT Weather File Generator, a software that not only downscales but also generates daily weather from general circulation models is used to overcome the coarse resolution of general circulation models (Jones and Thornton,
2013). The generated daily weather data characteristic of future climate scenarios was used to drive the CROPGROpigeonpea model.

For assessment of climate change and variability, Patel et al.(2018) analyzed 30 years weather data of Varanasi (from 1981 to 2010) and projected for years i.e. 2010, 2035, 2065 and 2095. They observed that the maximum temperature were increased $0.5^{\circ} \mathrm{C}$ to $1.9^{\circ} \mathrm{C}(1.5-5.8 \%)$, whereas, minimum temperature were also increased $0.5-2.0^{\circ} \mathrm{C}(2.7-10.3 \%)$ for projected years 2010 to 2095 . Solar radiation and rainfall would be decreased from 1.4-5.5 $\mathrm{MJm}^{-2} \mathrm{day}^{-1}$ (7.5-28.0\%) and 141.5-542 $\mathrm{mm}$ (14.6-56.1\%), respectively. The methodology of Patel et al.(2018) was adopted in order to study the impacts of climate change on pigeonpea yields. The main objective of present study was simulated projected yield of reference genotype of different pigeonpea maturity group under conditions of changing anticipated future radiation and temperature at Varanasi using MarkSim weather generator. 

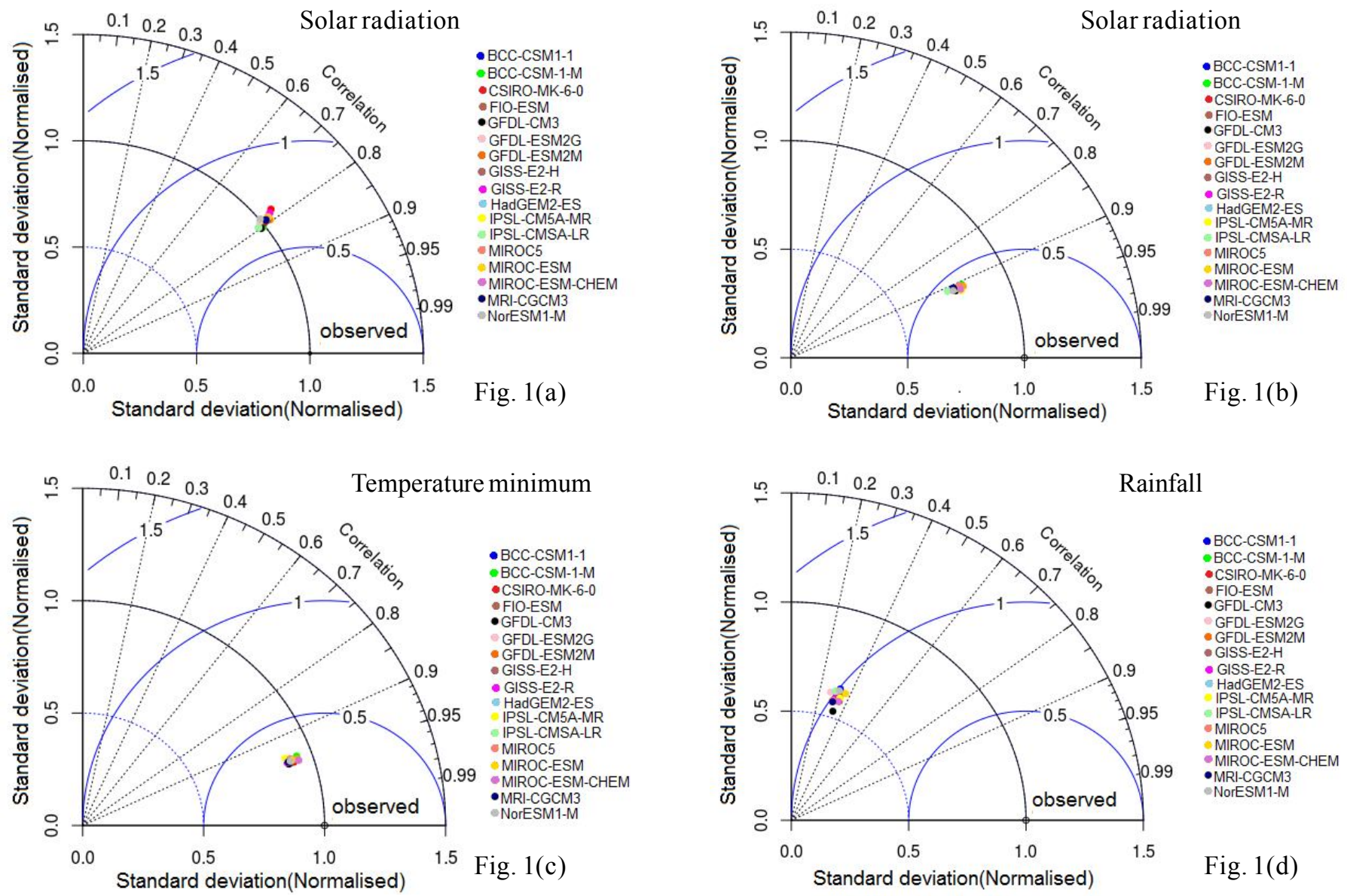

Fig.1 : Taylor diagrams for solar radiation, temperature maximum and minimum and precipitation, comparing observations with the weather generator models of MarkSim GCM at Varanasi for the year 2010.

\section{MATTERIALS AND METHODS}

Dailyweather data on maximum temperature, minimum temperature, solar radiation and rainfall from the India Meteorological Department(IMD), New Delhi and anthesis, maturity and grain yield data of reference cultivars of different pigeonpea maturity group collected from reports of All India Co-ordinated Pulse Improvement Project(AICPIP)/ All India Co-ordinated Reasearch Project on Pigeonpea(AICRPP) / All India Co-oridinated Research Project on Dryland Agriculture(AICRPDA)/International Crop Research Institute for Semi-Arid Tropic(ICRISAT)/Indian Institute of Pulse Research(IIPR)/ State Agriculture Universities (SAUs)/ Krishi Vigyan Kendra(KVKs)/State Department of Agriculture(SDAs) and works of many researcher shown in Table 1 were use for calibration and validation. The $n$ RMSE of day to anthesis, matrurity and grain yield of reference genotype of different pigeonpea maturity groups were showed its acceptable level viz. less than $10.0 \%$ as respective simulated values was closed to observed values (Table 1). The sensitivity analysis were carried out after the calibration and validation(Table 1) of The CROPGRO-pigeonpea model embedded in DSSATv4.7.5 model (Hoogenboom et al., 2019) in respect to anthesis, maturity and grain yield.

The minimum input data required to run the model for the studies of climate change impact includes: daily weather data (solar radiation, rainfall, maximum and minimum temperatures)generated from the website MarkSim DSSAT weather generator (http://gisweb.ciat.cgiar.org/ MarkSimGCM/) for Varanasi $\left(25^{\circ} 182\right.$ north latitude, $83^{\circ} 102$ east longitude and 76 meters above mean sea level) from 2010-2095 (Jones and Thornton, 2013); data of 99 replications of GFLD-CM3 model, with a spatial resolution of $1.2587 \times 2.5$ (latitude by longitude) (Dufresne et al., 2013) was selected. Data were downloaded in DSSAT friendly format for the following scenarios: RCP2.6, 4.5, 6.0 and RCP 8.5 with their respective projected years: 2010 , 2035,2065 and year 2095. The generated weather data of year 2010 with RCP 2.6, 4.5, 6.0 and RCP 8.5 were chosen as baseline for assessment of climate change impact in future years $(2035,2065$ and 2095). 
Table 1: Major pigeonpea maturity groups, reference cultivars, anthesis, maturity and grain yield used in calibration and validation (Data from reports of AICPIP/AICRPP/AICRPDA/ICRISAT/ IIPR/SAUs/SDAs and different researcher are used).

\begin{tabular}{|c|c|c|c|c|c|c|c|c|c|c|c|}
\hline $\begin{array}{l}\text { ICRISAT } \\
\text { maturity } \\
\text { group }\end{array}$ & $\begin{array}{l}\text { Maturity } \\
\text { group }\end{array}$ & $\begin{array}{l}\text { Reference } \\
\text { cultivars }\end{array}$ & $\begin{array}{l}50 \% \\
\text { Flowering } \\
\text { DAP }\end{array}$ & Obs. & Sim. & $\begin{array}{l}\text { Maturity } \\
\text { DAP }\end{array}$ & Obs. & Sim. & $\begin{array}{l}\text { Grain } \\
\text { yield } \\
\left(\mathrm{t} \mathrm{ha}^{-1}\right)\end{array}$ & Obs. & Sim. \\
\hline 00 & Super-early(SE) & MN 5 & $<50$ & 45 & 43 & $85-90$ & 85 & 82 & $1.5-2.0$ & 1.1 & 0.9 \\
\hline 0 & Extra-short(ES) & ICPL 88039 & $51-60$ & 50 & 55 & $90-110$ & 92 & 90 & $1.5-2.0$ & 1.8 & 1.9 \\
\hline I & Extra-Short(ES) & Prabhat & $61-70$ & 65 & 63 & $110-120$ & 101 & 100 & $1.5-2.5$ & 2.5 & 2.7 \\
\hline II & Short(S) & UPAS 120 & $71-80$ & 74 & 73 & $120-125$ & 115 & 115 & $1.5-2.5$ & 2.6 & 2.8 \\
\hline III & Short(S) & Т 21 & $81-90$ & 87 & 86 & $160-165$ & 140 & 131 & $2.0-3.0$ & 2.8 & 2.9 \\
\hline IV & Short(S) & ICP 6 & $91-100$ & 90 & 94 & $165-170$ & 155 & 151 & $2.0-3.5$ & 3.3 & 3.6 \\
\hline V & Short-medium(SM) & Maruti & $101-110$ & 105 & 105 & $170-180$ & 175 & 169 & $2.0-3.5$ & 3.2 & 3.6 \\
\hline $\mathrm{VI}$ & Medium(M) & Asha & $111-130$ & 115 & 115 & $180-200$ & 195 & 206 & $2.5-4.0$ & 3.8 & 4.0 \\
\hline VII & Medium(M) & ICP 7035 & $131-140$ & 136 & 134 & $200-210$ & 220 & 241 & $2.5-4.0$ & 3.8 & 4.1 \\
\hline VIII & Medium-long(ML) & Bahar & $141-160$ & 145 & 143 & $250-260$ & 270 & 271 & $2.5-4.5$ & 3.5 & 3.3 \\
\hline \multirow[t]{3}{*}{ IX } & Long(L) & MAL 13 & $>160$ & 155 & 156 & $240-250$ & 285 & 300 & $2.5-4.5$ & 4.5 & 4.8 \\
\hline & & RMSE & & 2.4 & & & 9.2 & & & 0.3 & \\
\hline & & nRMSE & & 2.5 & & & 5.5 & & & 8.8 & \\
\hline
\end{tabular}

Obs.: Observed, Sim.: Simulated, References- MN 5:Chauhan et al.(1998), Chauhan et al.(2002), Vales et al.(2012); ICPL 88039: Saxena et al.(2006), Vales et al.(2012); Prabhat: Kumar Rao and Dart(1987); UPAS 120: Sandhya and Singh(2018), Carberry et al.(2001); T 21: Kumar Rao and Dart(1987), Carberry et al.(2001), Saxena et al.(2019); ICP 6: Chauhan et al.(1992); Maruti: Saxena et al.(2006), Channabasavanna et al.(2015); Asha: Saxena et al.(2006), Channabasavanna et al.(2015); ICP 7035: Saxena et al.(2011); Bahar: Yadav and Singh(2009); MAL 13: Saxena et al.(2006)

\section{RESULTS AND DISCUSSION}

\section{Performance of models of MarkSim GCM}

For the performance of models, downloaded weather data of year 2010 of all 17 models of MarkSim GCM and compared with observed weather data of year 2010 as correlation, RMSE and normalized standard deviation in Taylor diagram. Results from the Taylor diagram suggests a good performance for the solar radiation Fig.1 (a) and temperature Fig.1 (b and c) variable by almost all the 17 models in MarkSim. For solar radiation, the correlation was high and ranged from 0.76 to 0.81 , the RMSE was low and ranges from 0.67 to $0.75 \mathrm{MJ} /$ day and the normalized standard deviation was some high and rages from 0.91 to $1.11 \mathrm{MJ} /$ day (Fig.1.a). For maximum temperature, the correlation was high and ranged from 0.90 to 0.93 , the RMSE was low and ranges from 0.45 to $0.49^{\circ} \mathrm{C} /$ day and the normalized standard deviation was also low and rages from 0.75 to $0.80{ }^{\circ} \mathrm{C} /$ day (Fig.1.b). For minimum temperature, the correlation was high and ranged from 0.94 to 0.95 , the RMSE was low and ranges from 0.35 to $0.39^{\circ} \mathrm{C} /$ day and the normalized standard deviation was also low and rages from 0.84 to $0.90 \mathrm{Deg} \mathrm{C/}$ day(Fig.1.c). For the generated rainfall, the models deviate significantly from observations. For the generated rainfall, the models deviate significantly from observations. The RMSE were large $(0.85-0.97 \mathrm{~mm} /$ day $)$ and the correlation was weak and ranges from 0.27 to 0.37 (Fig. 1.d). However, the GFDL-CM3 model ensemble performs better than any individual model as it has the largest correlation and least RMSE and normalized standard deviation. GFDL-CM3 is the best-performing individual model, followed closely by several others. Patel et al. (2018) also find that model GFDLCM3 has higher confidence and correlation between observed weather data for India.

\section{Validation of GFLD-CM3 weather generator model}

For validation of GFLD-CM3 model, simulated grain yield and phenology of reference genotypes of different pigeon pea maturity groups using GWD of GFLD-CM3 and compared with simulated of observed weather data. Simulated grain yield and phenology were near to simulate using observed weather data and presented in Table 2 
Table 2(a): Validation of GFLD-CM3 results against observed weather data of year 2010 of Varanasi district(Extra-short

\begin{tabular}{|c|c|c|c|c|c|c|c|}
\hline \multirow[t]{2}{*}{ Genotype } & \multirow[t]{2}{*}{ Scenario } & \multicolumn{2}{|c|}{ Grain yield $\left(\mathrm{tha}^{-1}\right)$} & \multicolumn{2}{|c|}{ Anthesis days (DAS) } & \multicolumn{2}{|c|}{ Maturity days (DAS) } \\
\hline & & Pro\# & Sim* & Pro\# & Sim* & Pro\# & Sim* \\
\hline \multirow[t]{7}{*}{ NM5 } & $\mathrm{RCP}(2.6)$ & 0.7 & 0.9 & 40 & 41 & 75 & 75 \\
\hline & $\mathrm{RCP}(4.5)$ & 0.8 & 0.9 & 39 & 41 & 75 & 75 \\
\hline & $\mathrm{RCP}(6.0)$ & 0.8 & 0.9 & 40 & 41 & 75 & 75 \\
\hline & $\mathrm{RCP}(8.5)$ & 0.8 & 0.9 & 39 & 41 & 74 & 75 \\
\hline & Mean & 0.8 & 0.9 & 39 & 41 & 75 & 75 \\
\hline & RMSE & 0.1 & & 1.57 & & 0.32 & \\
\hline & nRMSE & 7.7 & & 3.83 & & 0.42 & \\
\hline \multirow[t]{7}{*}{ ICPL88039 } & $\mathrm{RCP}(2.6)$ & 1.7 & 1.9 & 52 & 53 & 88 & 88 \\
\hline & $\mathrm{RCP}(4.5)$ & 1.8 & 1.9 & 52 & 53 & 88 & 88 \\
\hline & $\mathrm{RCP}(6.0)$ & 1.7 & 1.9 & 52 & 53 & 88 & 88 \\
\hline & $\mathrm{RCP}(8.5)$ & 1.8 & 1.9 & 51 & 53 & 87 & 88 \\
\hline & Mean & 1.8 & 1.9 & 52 & 53 & 88 & 88 \\
\hline & RMSE & 0.1 & & 1.16 & & 0.58 & \\
\hline & nRMSE & 5 & & 2.19 & & 0.66 & \\
\hline \multirow[t]{7}{*}{ PRABHAT } & $\mathrm{RCP}(2.6)$ & 2.6 & 2.7 & 60 & 61 & 98 & 98 \\
\hline & $\mathrm{RCP}(4.5)$ & 2.6 & 2.7 & 60 & 61 & 98 & 98 \\
\hline & $\mathrm{RCP}(6.0)$ & 2.4 & 2.7 & 60 & 61 & 98 & 98 \\
\hline & $\mathrm{RCP}(8.5)$ & 2.6 & 2.7 & 59 & 61 & 97 & 98 \\
\hline & Mean & 2.5 & 2.7 & 60 & 61 & 98 & 98 \\
\hline & RMSE & 0.2 & & 1.49 & & 0.36 & \\
\hline & nRMSE & 7 & & 2.44 & & 0.37 & \\
\hline
\end{tabular}

Pro\#: Projected, Sim*: Simulated

(a,b\&c). The $n$ RMSE of day to anthesis and maturity of reference genotype of different pigeon pea maturity groups were showed its acceptable level viz. less than $6.0 \%$. The $n$ RMSE of grain yield of reference genotype of different maturity groups was also support to simulation of impact of climate change of pigeonpea crop using generated weather data for future climatology. However, validation has been done with simulated phenology and grain yield using observed weather data of year 2010 only.

\section{Consequences of climate change on pigeon pea yield}

Percent changes in yield were evaluated by comparing the future pigeon pea yields of each reference genotype of different maturity groups to the baseline yields of projected year of 2010 with its scenario (Table 3.a). Effect of climate change on pigeon pea grain yield were studied for projected years i.e. 2035, 2065 and 2095, yield decreased prevail at all scenario viz. RCP 2.6, RCP 4.5, RCP 6.0 and RCP 8.5. Short duration genotypes (MN5, ICPL88039, Prabhat, UPAS120) showed progressively higher decrease in yield as compared to medium (Maruti, Asha, ICP7035) and long (Bahar, MAL13) duration genotypes with each successive increase in scenatio from RCP 2.6 to RCP 8.5 and projected year from 2010 to 2095 . The maximum yield decreased in the scenario RCP 8.5 , which ranged from - $66 \%(\mathrm{MN} 5)$ to $-14 \%$ (Bahar) were more extreme than emission scenarios (RCP 2.6, 4.5 and 6.0), which were between $-3 \%$ to $-41 \%$ in genotype MN5 to $3 \%$ to $-12 \%$ in genotype Bahar. These results show RCP 8.5 (-14\%) as the most resilient scenario, and RCP $2.6(-5 \%)$ as least resilient scenario to climate change on average yield basis. Projected year 2035 (-7\%) was the least vulnerable and year 2095(19\%) the most vulnerable under all emission scenario. Yadav et al. (2016) and Patel et al. (2018b) found that substantial pigeonpea 
Table 2(b): Validation of GFLD-CM3 results against observed weather data of year 2010 of Varanasi district (short and shortmedium varieties)

\begin{tabular}{|c|c|c|c|c|c|c|c|}
\hline \multirow[t]{2}{*}{ Genotype } & \multirow[t]{2}{*}{ Scenario } & \multicolumn{2}{|c|}{ Grain yield $\left(\mathrm{t} \mathrm{ha}^{-1}\right)$} & \multicolumn{2}{|c|}{ Anthesis days (DAS) } & \multicolumn{2}{|c|}{ Maturity days (DAS) } \\
\hline & & Pro\# & Sim* & Pro\# & Sim* & Pro\# & Sim* \\
\hline \multirow[t]{7}{*}{ UPAS120 } & $\mathrm{RCP}(2.6)$ & 2.8 & 2.8 & 70 & 71 & 113 & 113 \\
\hline & $\mathrm{RCP}(4.5)$ & 3.0 & 2.8 & 70 & 71 & 113 & 113 \\
\hline & $\mathrm{RCP}(6.0)$ & 2.8 & 2.8 & 70 & 71 & 114 & 113 \\
\hline & $\mathrm{RCP}(8.5)$ & 3.0 & 2.8 & 69 & 71 & 113 & 113 \\
\hline & Mean & 2.9 & 2.8 & 70 & 71 & 113 & 113 \\
\hline & RMSE & 0.1 & & 1.16 & & 0.36 & \\
\hline & nRMSE & 3 & & 1.63 & & 0.32 & \\
\hline \multirow[t]{7}{*}{ Т 21} & $\mathrm{RCP}(2.6)$ & 3.0 & 2.9 & 84 & 84 & 129 & 129 \\
\hline & $\mathrm{RCP}(4.5)$ & 3.1 & 2.9 & 84 & 84 & 129 & 129 \\
\hline & $\mathrm{RCP}(6.0)$ & 3.0 & 2.9 & 84 & 84 & 129 & 129 \\
\hline & $\mathrm{RCP}(8.5)$ & 3.1 & 2.9 & 83 & 84 & 129 & 129 \\
\hline & Mean & 3.1 & 2.9 & 84 & 84 & 129 & 129 \\
\hline & RMSE & 0.1 & & 0.41 & & 0.31 & \\
\hline & nRMSE & 5 & & 0.49 & & 0.24 & \\
\hline \multirow[t]{7}{*}{ ICP6 } & $\mathrm{RCP}(2.6)$ & 3.3 & 3.6 & 92 & 92 & 150 & 149 \\
\hline & $\mathrm{RCP}(4.5)$ & 3.2 & 3.6 & 91 & 92 & 150 & 149 \\
\hline & $\mathrm{RCP}(6.0)$ & 3.4 & 3.6 & 91 & 92 & 150 & 149 \\
\hline & $\mathrm{RCP}(8.5)$ & 3.3 & 3.6 & 91 & 92 & 150 & 149 \\
\hline & Mean & 3.3 & 3.6 & 91 & 92 & 150 & 149 \\
\hline & RMSE & 0.2 & & 0.62 & & 1.03 & \\
\hline & nRMSE & 7 & & 0.67 & & 0.69 & \\
\hline \multirow[t]{7}{*}{ MARUTI } & $\mathrm{RCP}(2.6)$ & 3.7 & 3.6 & 103 & 103 & 168 & 167 \\
\hline & $\mathrm{RCP}(4.5)$ & 4.0 & 3.6 & 103 & 103 & 169 & 167 \\
\hline & $\mathrm{RCP}(6.0)$ & 3.5 & 3.6 & 103 & 103 & 168 & 167 \\
\hline & $\mathrm{RCP}(8.5)$ & 3.5 & 3.6 & 103 & 103 & 169 & 167 \\
\hline & Mean & 3.7 & 3.6 & 103 & 103 & 103 & 103 \\
\hline & RMSE & 0.2 & & 0.16 & & 1.16 & \\
\hline & nRMSE & 5 & & 0.16 & & 0.75 & \\
\hline
\end{tabular}

Pro\#: Projected, Sim*: Simulated

grain yield decreased with increasing maximum and minimum temperature from normal temperature. Devasirvatham et al. (2012) explained that the high temperatures (40/25) reduced pod set and seed number by reducing pollen viability and pollen production per flower, per cent pollen germination. High temperature during reproductive stage causes abnormal development of the male/ female reproductive tissues, poor production of growth regulators in sink tissues, reduced supply of photosynthates, pollen production, pollen viability, fertilization, pod, seed-set; all of which lead to poor productivity in pigeonpea (Kesava Rao et al., 2013).

\section{Consequences of climate change on phenology of pigeonpea crop}

The traditional varieties of pigeonpea grown are mainly medium and long-duration types. Reproductive phase of development coincides with the period when temperatures are cool and day length is short. Consequently, it is tempting to overlook the effect of temperature and conclude that 
Table 2(c): Validation of GFLD-CM3 results against observed weather data of year 2010 of Varanasi district(medium to long varieties)

\begin{tabular}{|c|c|c|c|c|c|c|c|}
\hline \multirow[t]{2}{*}{ Genotype } & \multirow[t]{2}{*}{ Scenario } & \multicolumn{2}{|c|}{ Grain yield $\left(\mathrm{t} \mathrm{ha}^{-1}\right)$} & \multicolumn{2}{|c|}{ Anthesis days (DAS) } & \multicolumn{2}{|c|}{ Maturity days (DAS) } \\
\hline & & Pro\# & Sim* & Pro\# & Sim* & Pro\# & Sim* \\
\hline \multirow[t]{7}{*}{ ASHA } & $\mathrm{RCP}(2.6)$ & 4.2 & 4.0 & 113 & 113 & 199 & 204 \\
\hline & $\mathrm{RCP}(4.5)$ & 4.1 & 4.0 & 113 & 113 & 190 & 204 \\
\hline & $\mathrm{RCP}(6.0)$ & 4.5 & 4.0 & 112 & 113 & 198 & 204 \\
\hline & $\mathrm{RCP}(8.5)$ & 4.0 & 4.0 & 112 & 113 & 196 & 204 \\
\hline & Mean & 4.2 & 4.0 & 112 & 113 & 196 & 204 \\
\hline & RMSE & 0.3 & & 0.55 & & 8.59 & \\
\hline & nRMSE & 7 & & 0.49 & & 4.21 & \\
\hline \multirow[t]{7}{*}{ ICP7035 } & $\mathrm{RCP}(2.6)$ & 4.1 & 4.1 & 134 & 132 & 239 & 239 \\
\hline & $\mathrm{RCP}(4.5)$ & 4.2 & 4.1 & 134 & 132 & 238 & 239 \\
\hline & $\mathrm{RCP}(6.0)$ & 3.9 & 4.1 & 134 & 132 & 239 & 239 \\
\hline & $\mathrm{RCP}(8.5)$ & 4.2 & 4.1 & 134 & 132 & 241 & 239 \\
\hline & Mean & 4.1 & 4.1 & 134 & 132 & 239 & 239 \\
\hline & RMSE & 0.1 & & 2.04 & & 1.11 & \\
\hline & nRMSE & 2 & & 1.55 & & 0.46 & \\
\hline \multirow[t]{7}{*}{ BAHAR } & $\mathrm{RCP}(2.6)$ & 3.5 & 3.3 & 146 & 141 & 268 & 269 \\
\hline & $\mathrm{RCP}(4.5)$ & 3.2 & 3.3 & 146 & 141 & 273 & 269 \\
\hline & $\mathrm{RCP}(6.0)$ & 3.0 & 3.3 & 146 & 141 & 271 & 269 \\
\hline & $\mathrm{RCP}(8.5)$ & 3.2 & 3.3 & 147 & 141 & 271 & 269 \\
\hline & Mean & 3.2 & 3.3 & 146 & 141 & 271 & 269 \\
\hline & RMSE & 0.2 & & 5.28 & & 2.42 & \\
\hline & nRMSE & 5 & & 3.74 & & 0.90 & \\
\hline \multirow[t]{7}{*}{ MAL 13} & $\mathrm{RCP}(2.6)$ & 4.5 & 4.8 & 162 & 154 & 290 & 298 \\
\hline & $\mathrm{RCP}(4.5)$ & 4.6 & 4.8 & 163 & 154 & 297 & 298 \\
\hline & $\mathrm{RCP}(6.0)$ & 4.4 & 4.8 & 161 & 154 & 286 & 298 \\
\hline & $\mathrm{RCP}(8.5)$ & 4.7 & 4.8 & 164 & 154 & 294 & 298 \\
\hline & Mean & 4.6 & 4.8 & 162 & 154 & 292 & 298 \\
\hline & RMSE & 0.3 & & 8.54 & & 7.16 & \\
\hline & nRMSE & 5 & & 5.54 & & 2.40 & \\
\hline
\end{tabular}

Pro\#: Projected, Sim*: Simulated

flowering is triggered only by short days. If sensitivity in phenology leads to a delay in maturity, it is likely to result in yield reduction in those areas where rainfall duration is short or where the crop depends on residual soil moisture. Both the extra-short and short-duration genotypes flowered within 100 days from sowing but the medium and longduration genotypes flowered later. The extra-short duration genotype has the highest optimum temperature while the long-duration genotype has the lowest optimum temperature. The extra-short and short-duration genotypes had high optimum temperature for time to flower with cool temperatures lengthening and warm temperatures shortening the duration. For medium-duration genotypes (Maruti, Asha, ICP7035), temperatures during the vegetative stages are high but low during the reproductive phases. By contrast, the long-duration genotype (Bahar, MAL13) was insensitive 


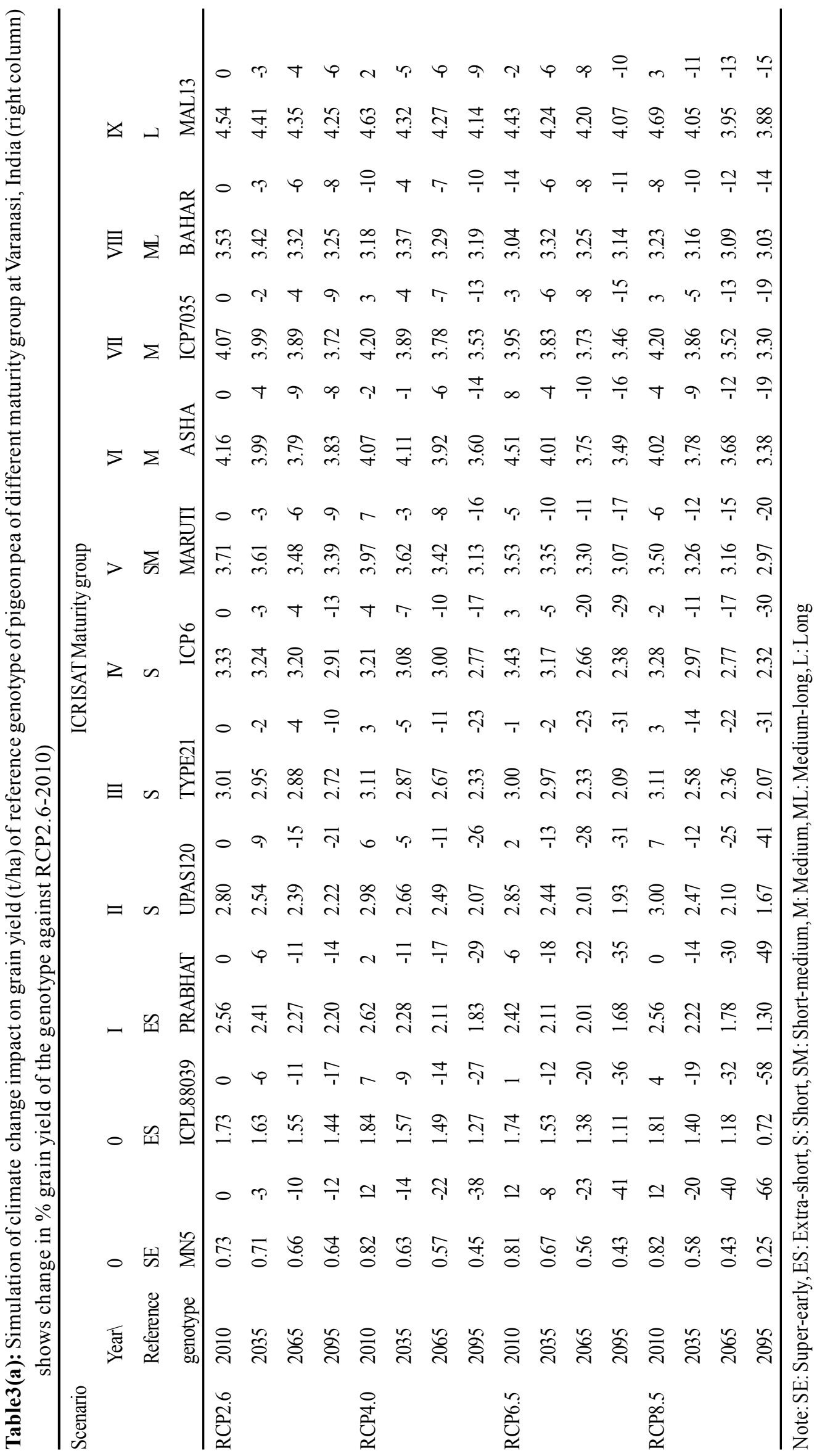




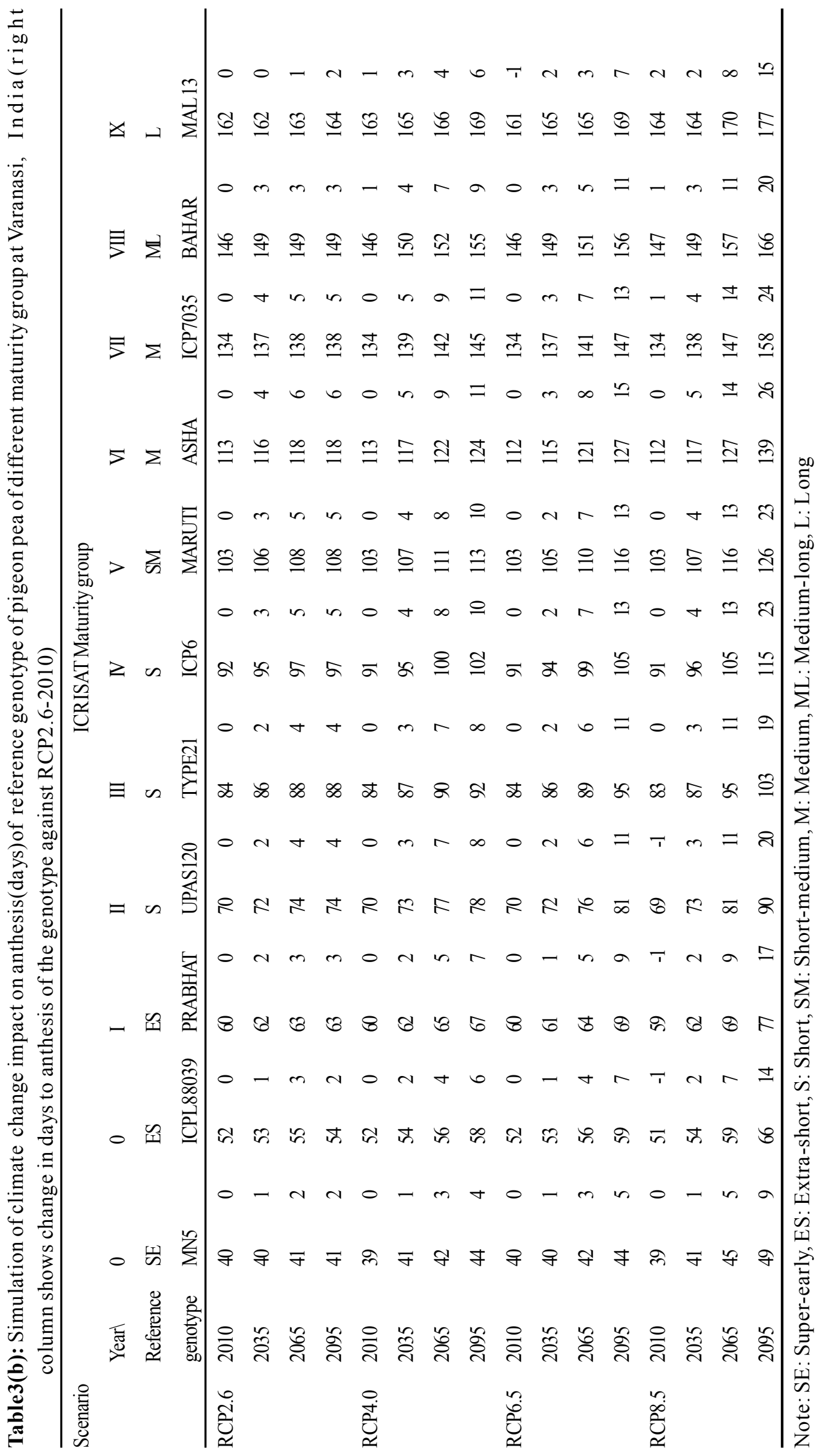




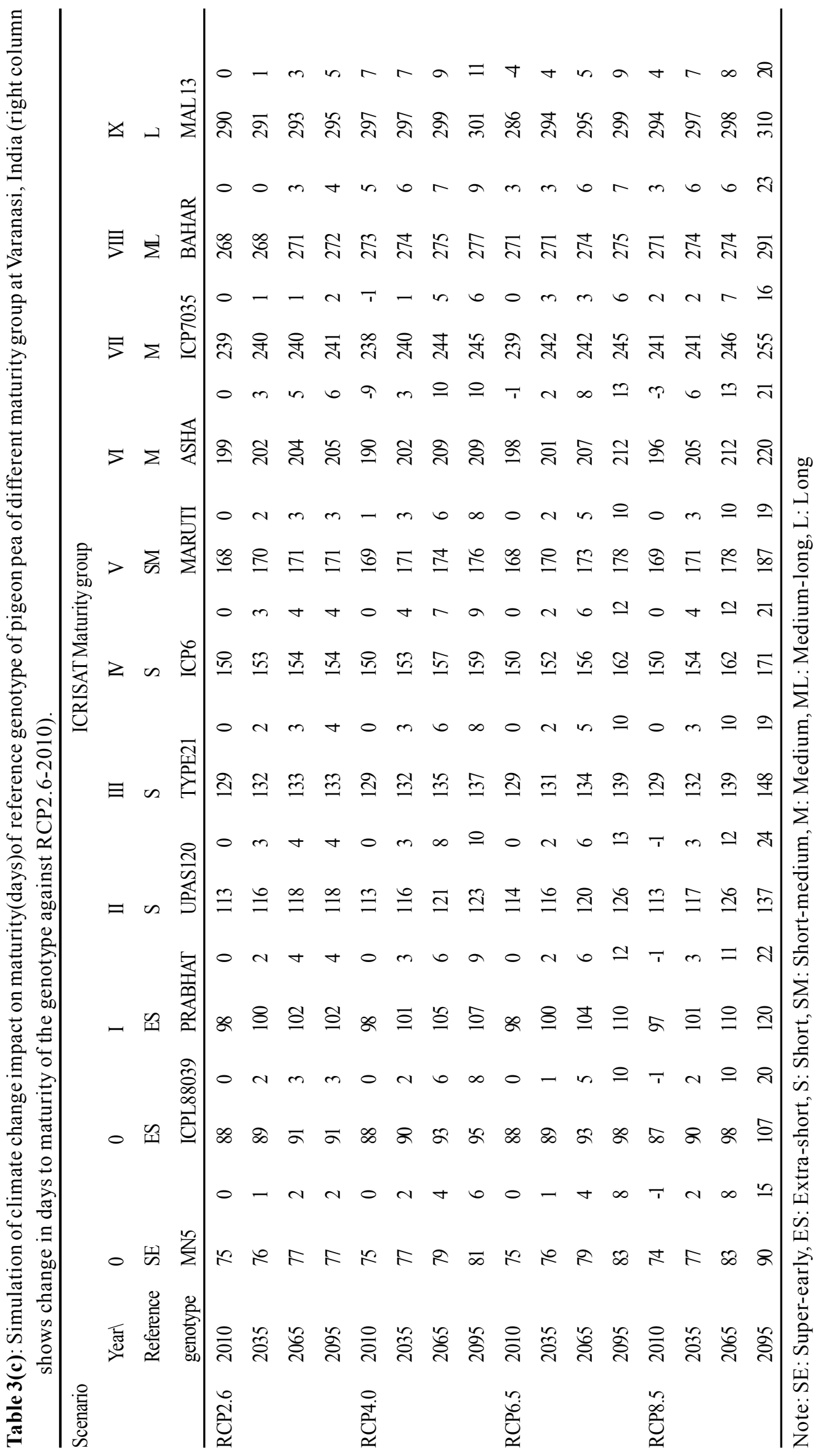


to variation in temperature likely because it is a land race from northern India where temperatures during the crop's growth cycle vary from $>40^{\circ} \mathrm{C}$ to sub-zero. This study also showed that with the exception of genotypes from northern India, pigeonpea has specific and narrow adaptation. For photoperiod, the long duration genotypes (Bahar, MAL13) were the most sensitive, followed by medium-duration genotypes (Maruti, Asha and ICP 7035), which were intermediate in sensitivity. The short-duration genotype (UPAS120, T 21 and ICP6) was insensitive and extra-shortduration genotype (MN5 and ICPL 88039, Prabhat) was the least sensitive to photoperiod. In similar studies, mediumand long-duration cultivars delayed flowering by 150 days in response to photoperiod (Carberry et al., 2001).

In our study, model simulated phenology viz. days to anthesis and days to maturity reveal how RCPs and their projected years would lengthen critical crop stages, all of which are detrimental for plant and grain size due to enhanced respiration and poor translocation of assimilate from source to sink (Harrison et al., 2011). The impact of delayed reproductive stages anthesis (Table 3.b), maturity(Table 3.c) were evident in all scenarios (RCP 2.6, 4.5, 6.0 and RCP $8.5)$ and increased with increasing projected years. Yadav $e t$ al. (2016) and Patel et al. (2018b) found that days to anthesis and maturity increased when increasing maximum and minimum temperature from normal temperature. Highest increase of days to anthesis and days to maturity at RCP 8.5 during 2095 while, lowest in at RCP 2.6 during 2010. In all scenarios, increased maximum and minimum temperature delaying on anthesis and maturity phase irrespective of genotypes.

\section{CONCLUSIONS}

The present investigation was to assessment of impact of climate change on reference genotype of different pigeon pea maturity group using generated weather data of MarkSim GCM of RCP scenario of IPCC and their projected years for Varanasi region. The study concluded that climate change could potentially result in decreasing yield of all reference genotypes in different pigeon pea maturity groups at Varanasi (Uttar Pradesh), north India. Maximum grain yields were decrease with RCP8.5 at all projected years, which show most vulnerable RCP in comparison to others RCP. Also, the study of climate change showed adverse effect on the physiology. There lies threat of climate change and its anticipated effect on pigeon pea yield in this region as revealed in this study. Agriculture scientists, therefore, should keep this information in mind while developing new variety, technology and management etc. for pigeon pea growing in this region. Information generated in this study can also be utilised for decision support system and making planning at large scale.

\section{REFERENCES}

Carberry, P.S.; Ranganathan, R.; Reddy, L.J.; Chauhan,Y.S. and Robertson, M.J. (2001). Predicting growth and development of pigeonpea: Flowering response to photoperiod. Field Crops Research 69:151-162

Channabasavanna, A.S.; Kitturmath, M.S. and Rajakumar, H.(2015). Standardization of sowing date and genotypes of pigeon pea [Cajanus cajan (L.) Millsp.] under erratic rainfall conditions in northern dry zone of Karnataka. Karnataka J. Agric. Sci., 28(4): 604-605.

Chauhan, Y.S.; Johansen, C.; Jung-Kyung Moon, Yeong-Ho Lee and Suk-Ha Lee(2002). Photoperiod responses of extra-short-duration pigeon pea lines developed at different latitudes. Crop Sci. 42:1139-1146.

Chauhan, Y.S.; Wallace, D.H.; Johansen, C. and Singh, Laxman (1998). Genotype-by-environment interaction effect on yield and its physiological bases in short-duration pigeon pea. Field Crops Research 59:141-150.

Chauhan, Y.S.; Johansen, C. and Venkataratnam, N.(1992). Effect of phosphorous deficiency on phenology and yield components of short-duration pigeon pea. Trop. Agric.(Trinidad) 69(3):335-338.

Devasirvatham, V.; Gaur, P.M.; Mallikarjuna, N.; Tokachichu, R.N.; Trethowan, R.M. and Tan, D.K. (2012). Effect of high temperature on the reproductive development of chickpea genotypes under controlled environments. Fun. Plant Biol., 39(12): 1009-1018.

Dufresne, J.L.; Foujols, M.; Denvil, S. ; Caubel, A.; Marti, O.; Aumont, O. and Vuichard, N. (2013). Climate change projections using the IPSL-CM5 earth system model: from CMIP3 toCMIP5. Climate Dynamics, 40.

Harrison, L.; Michaelsen, J.; Funk, C. and Husak, G. (2011). Effects of temperature changes on maize production in Mozambique. Climate Research 46 (3):211-222.

Hoogenboom, G.; Jones, J.W.; Wilkens, P.W. ; Porter, C.H.; Boote, K.J.; Hunt, L.A.; Singh, U.; Lizaso, J.I.; White, J.W.; Uryasev, O.; Ogoshi, R.; Koo, J.; Shelia, V. and Tsuji, G.Y. (2019). Decision Support System for AgrotechnologyTransfer(DSSAT) Version v4.7.5 (http:/ /dssat.net). DSSAT Foundation, Prosser, Washington. 
International Panel on Climate Change (IPCC)(2014). Summary for Policy Makers. Climate Change 2014: Impacts, Adaptation and Vulnerability-Contributions of the Working GroupII to the Fifth Assessment Report.

Jones, P.G. and Thornton, P.K. (2013). Generating downscaled weatherdata froma suite of climate models for agricultural modelling applications. Agric. Syst. 114:1-5.

Kesava Rao, A.V.R.; Wani, S.P.; Komuravelly, S.; Singh, P.; Bairagi, S.D. and Ramadevi, O. (2013).Assessing impacts of projected climate on pigeonpea crop at Gulbarga. $J$. Agrometeorol., 15(Special Issue-II): 32-37.

Kumar Rao, J.V.D.K. and Dart, P.J.(1987). Nodulation, nitrogen fixation and nitrogen uptake in pigeonpea (Cajanus cajan (L.) Millsp) of different maturity groups. Plant \& Soil 99:255-266.

Patel, C.; Nema,A.K.; Singh, R.S.; Yadav, M.K.; Singh, K.K.; Singh, S.K.; Rai,P.K. andSingh, S.M.(2018a). Assessment of climate change impact on wheat crop using MarkSim GCM for Varanasi region of Uttar Pradesh (India). J. Agrometeorol. 20(3):216-218.

Patel, D. D.; Pandey, Vyas; Gurjar, Ramesh and Patel, H. P.(2018b). Effect of intra-seasonal variation in temperature and rainfall on seed yield of pigeon pea cultivars using CROPGRO model. J. Agrometeorol. 20(4):286-292. 